\title{
Assessing factors associated with poor maternal mental health among mothers of children born small and sick at 24-47 months in rural Rwanda
}

Marie Claire Abimana ${ }^{1 \dagger}$, Egide Karangwa ${ }^{1 * \dagger}$, Ibrahim Hakizimana ${ }^{1}$, Catherine M. Kirk' ${ }^{1}$ Kathryn Beck ${ }^{1}$, Ann C. Miller ${ }^{2}$, Silas Havugarurema ${ }^{3}$, Sadallah Bahizi ${ }^{3}$, Alphonsine Uwamahoro ${ }^{3}$, Kim Wilson ${ }^{4}$, Mathieu Nemerimana ${ }^{1}$ and Alphonse Nshimyiryo ${ }^{1}$

\begin{abstract}
Background: Global investments in neonatal survival have resulted in a growing number of children with morbidities surviving and requiring ongoing care. Little is known about the caregivers of these children in low- and middle-income countries, including maternal mental health which can further negatively impact child health and development outcomes. We aimed to assess the prevalence and factors associated with poor maternal mental health in mothers of children born preterm, low birthweight (LBW), and with hypoxic ischemic encephalopathy (HIE) at 24-47 months of age in rural Rwanda.
\end{abstract}

Methods: Cross-sectional study of children 24-47 months born preterm, LBW, or with HIE, and their mothers discharged from the Neonatal Care Unit (NCU) at Kirehe Hospital between May 2015-April 2016 or discharged and enrolled in a NCU follow-up program from May 2016-November 2017. Households were interviewed between October 2018 and June 2019. Mothers reported on their mental health and their child's development; children's anthropometrics were measured directly. Backwards stepwise procedures were used to assess factors associated with poor maternal mental health using logistic regression.

Results: Of 287 total children, 189 (65.9\%) were born preterm/LBW and 34.1\% had HIE and 213 (74.2\%) screened positive for potential caregiver-reported disability. Half $(n=148,51.6 \%)$ of mothers reported poor mental health. In the final model, poor maternal mental health was significantly associated with use of violent discipline (Odds Ratio [OR] 2.29, 95\% Confidence Interval [CI] 1.17.4.45) and having a child with caregiver-reported disability (OR 2.96, 95\% $\mathrm{Cl} 1.55,5.67)$. Greater household food security (OR $0.80,95 \% \mathrm{Cl} 0.70-0.92)$ and being married $(\mathrm{OR}=0.12,95 \% \mathrm{Cl}$ 0.04-0.36) or living together as if married $(\mathrm{OR}=0.13,95 \% \mathrm{Cl} 0.05,0.37)$ reduced the odds of poor mental health.

\footnotetext{
* Correspondence: ekarangwa@pih.org

${ }^{\dagger}$ Marie Claire Abimana and Egide Karangwa contributed equally to this work.

${ }^{1}$ Partners In Health/Inshuti Mu Buzima, Rwinkwavu, Rwanda

Full list of author information is available at the end of the article
}

\section{BMC}

C The Author(s). 2020 Open Access This article is licensed under a Creative Commons Attribution 4.0 International License, which permits use, sharing, adaptation, distribution and reproduction in any medium or format, as long as you give appropriate credit to the original author(s) and the source, provide a link to the Creative Commons licence, and indicate if changes were made. The images or other third party material in this article are included in the article's Creative Commons licence, unless indicated otherwise in a credit line to the material. If material is not included in the article's Creative Commons licence and your intended use is not permitted by statutory regulation or exceeds the permitted use, you will need to obtain permission directly from the copyright holder. To view a copy of this licence, visit http://creativecommons.org/licenses/by/4.0/. The Creative Commons Public Domain Dedication waiver (http://creativecommons.org/publicdomain/zero/1.0/) applies to the data made available in this article, unless otherwise stated in a credit line to the data. 


\begin{abstract}
(Continued from previous page)
Conclusions: Half of mothers of children born preterm, LBW and with HIE had poor mental health indicating a need for interventions to identify and address maternal mental health in this population. Mother's poor mental health was also associated with negative parenting practices. Specific interventions targeting mothers of children with disabilities, single mothers, and food insecure households could be additionally beneficial given their strong association with poor maternal mental health.
\end{abstract}

Keywords: Maternal mental health, Prematurity, Low birthweight, Rwanda, Nurturing care, Toxic stress, Developmental disability

\section{Background}

Globally, over 20 million children are born at low birthweight (LBW < $2500 \mathrm{~g}$ ) each year, nearly 15 million children are born preterm (gestational age $<37$ weeks), 32 million infants are born small for their gestational age, and 1 million newborns have neonatal encephalopathy due to birth complications [1-4]. A third of neonatal deaths are due to complications of prematurity and a quarter are due to intrapartum complications such as birth asphyxia which leads to hypoxic ischemic encephalopathy (HIE) [5]. Children born preterm, LBW or with HIE and other medical vulnerabilities also have an increased risk for poor physical and psychosocial developmental outcomes [6, 7]. In turn, mothers of these children are vulnerable to psychological distress from caring responsibilities and ongoing challenges such as poor growth that many of these children may experience [8-11]. Studies that compared parenting stress between mothers of preterm and term babies revealed that having a preterm child is associated with high levels of depressive symptoms and stress $[9,12-14]$.

Understanding the burden of poor mental health on mothers of children born small and sick is essential to inform interventions that promote the well-being of parents and better developmental outcomes of their children. While effects of maternal stress and preterm birth outcomes may vary by context, poor caregiver's mental health is associated with poor infant growth and cognitive development [13, 15-19]. However, treatment approaches based on increasing social support and enhancing mother-infant interactions have been proven effective to improve maternal mental health status and simultaneously improve child developmental status [10, 20].

Despite the effectiveness of treatment, in most lowand middle-income countries, maternal mental health services have not been incorporated into the primary health care system [21], and $76-85 \%$ patients with mental health problems do not receive any intervention [19]. In Africa and Asia, the prevalence of maternal depression is estimated at $15-28 \%$ [10]. Additionally, in a postconflict country, such as Rwanda, there is an increased likelihood of maternal distress disorders [22] which may be further exacerbated in cases of prematurity, LBW and HIE. Poor maternal mental health has been identified among caregivers of children born small or with HIE in high-income countries, in part due to the stresses of uncertain survival and potential ongoing impairment among children with these conditions [23, 24]. However, despite some small studies identifying a high prevalence of maternal depression and anxiety in areas of Rwanda $[25,26]$, the country's decentralized mental health services are focused on more severe mental illnesses, such as schizophrenia [27]. Like many other low- and middleincome countries there are no specific interventions for maternal depressive symptoms and anxiety [28]. Thus, maternal depression and other distress disorders which are frequently complicated by social, emotional, and financial difficulties [29], go unaddressed. The existing evidence suggests that interventions to improve maternal mental health would also contribute to reducing the burden of childhood undernutrition so would be mutually beneficial to mother and child [30].

Rwanda has made efforts in improving outcomes for children in early childhood through improved health services at health facilities, community-based interventions for children under 5 years including community case management and community nutritional screening, as well as a growing priority on promoting optimal early childhood development [31, 32]. In Rwanda, $10 \%$ of newborns are born preterm each year and $7 \%$ are born with LBW [33]. Prematurity/LBW and HIE are two of the three leading causes of admission to hospital neonatal care units in Rwanda [34]. However, to our knowledge, mental health among mothers of children with these perinatal risk factors has not been studied in Rwanda. Therefore, this study aims to assess the prevalence and factors associated with poor maternal mental health among mothers of children born preterm, LBW or with HIE when the children are ages 24-47 months.

\section{Methods}

\section{Study setting}

This study was conducted in Kirehe District in the Eastern Province of Rwanda. Kirehe District is served by Kirehe District Hospital (KDH), which is operated by the 
Rwanda Ministry of Health (MOH) and serves a catchment of over 400,000 people [35] plus a refugee camp of 60,000 people [36]. Kirehe District Hospital has been supported by Partners In Health/Inshuti Mu Buzima since 2008. The hospital has provided specialized inpatient neonatal care for preterm and LBW newborns, as well as newborns with HIE and other medical conditions since 2012. In May 2016, a Pediatric Development Clinic (PDC) was established at Kirehe District Hospital through the collaboration of Partners In Health/ Inshuti $\mathrm{Mu}$ Buzima and the $\mathrm{MOH}$ to provide clinical, nutritional, and developmental follow-up to children discharged from the Kirehe District Hospital neonatol care unit (NCU). Detailed information on PDC can be found elsewhere [37].

\section{Study design and population}

This was a cross-sectional study that included children aged 24-47 months born with prematurity, LBW, or HIE, and discharged from the NCU at Kirehe District Hospital between May 2015 and April 2016 or enrolled in the PDC from May 2016 to November 2017. Primary caregivers of these children were included in this study if they were the biological mothers and if data on their mental health status was collected.

\section{Data collection}

Data were collected between October 2018 and June 2019 by a trained team of Partners In Health/Inshuti $\mathrm{Mu}$ Buzima data collectors. Data collectors conducted household interviews in Kinyarwanda with primary caregivers of eligible children, and measured anthropometrics and developmental indicators for children. Due to limitations in literacy, the data collector conducted the consent process and interview verbally and written confirmation of consent was provided by participants with a signature or fingerprint. The collected data included caregiver-reported child's developmental status, child's caregiver-reported disability status, child feeding, caregiver mental health, household socio-economic status, child discipline practices, and early stimulation activities. The child's nutritional status was measured directly.

\section{Measures}

Primary outcome Maternal mental health was measured using the Hopkins Symptom Checklist, which has been validated in Rwanda. It is a 25 item measure of symptoms of anxiety and depression with the total score being a mean of all items; a score $>1.75$ is considered high level of anxiety and depression symptoms [38]. The full questionnaire is available in Supplementary File 1.
Covariates Stunting (low height-for-age), wasting (low weight-for-height), and underweight (low weight-forage) were measured using standard anthropometric procedures to capture weight and height (or length) and compared to the WHO Child Growth Standards [39]. The cutoff point for severe malnutrition was a z-score less than -3 standard deviations and moderate malnutrition is a z-score less than -2 standard deviations using the WHO Child Growth Standards.

Home environment was assessed using UNICEF's Family Care Indicators [40], which measure early learning activities, availability of play materials, and exposure to inadequate care. Inadequate care is when caregivers reported that the child was left alone, or the child was cared for by another child less than 10 years of age, for 1 hour or more in the past week. The UNICEF Multiple Indicator Cluster Survey measure of violent discipline [41] was also used. Exposure to violent discipline was defined as caregiver-reported use of any psychological aggression (i.e., yelling, name calling) or physical punishment (i.e., hitting, spanking) to the child in the past month.

Household socioeconomic status was measured using an asset index which was analyzed using principal component analysis for a measure of relative wealth in our sample; households were grouped into tertiles representing the poorest, the middle, and the wealthiest groups. In addition, the Rwandan "Ubudehe" categorization was collected, which is a Rwandan community-based ranking of wealth status. Households are categorized in to 4 groups with the first category being the extremely poor and qualifying for government social services including free health insurance, and the fourth being the wealthiest category.

Child disability was measured using the Ten Questions Questionnaire [42], which is a caregiver-reported screening tool for detecting impairments in physical development, hearing, vision, and communication. Children whose mother responded to yes on any one impairment were considered at risk for moderate to severe disability.

Child development was measured using the Ages and Stages Questionnaire (ASQ-3) [43]. The ASQ-3 asks 30 age-specific questions across communication, gross motor, fine motor, personal social, and problem solving domains. Children are screened as "at risk for developmental delay" if they fall below the standard Westernnormed cut-point in any one of the five domains.

Social support was measured using the Inventory of Socially Supportive Behaviors which had been previously adapted to Rwanda and is scored as a mean score of all items with 1 being the minimum score (low social support) and 5 being the maximum [44, 45].

Months of Adequate Household Food Provisioning is a way to measure self-reported household food access over the past year [46]. 


\section{Data analysis}

We described socio-economic and demographic characteristics, child nutrition and development, home environment and maternal mental health using frequencies and percentages for categorical variables and mean and standard deviation (SD) or median and interquartile range (IQR) for continuous variables. Bivariate associations between maternal mental health status and each covariate was assessed using Fisher's exact (categorical) and t-test (continuous) or Wilcoxon rank sum test if continuous measures were not normally distributed (social support, months of adequate household food provisioning). Backwards stepwise techniques were used to build a multivariable logistic regression model to investigate factors associated with poor maternal mental health. We included in the full model all variables associated with maternal mental health at $\alpha=0.20$ in the bivariate analysis. Manual removal of variables was completed following backwards stepwise procedures and the final model included only variables significant at $\alpha=0.05$.

\section{Results}

Our study included 287 children born preterm/LBW $(n=189,65.9 \%)$ or with HIE $(n=98,34.1 \%)$ and their biological mothers (Table 1). Of these children, 50.9\% $(n=146)$ were boys and $63.1 \%(n=181)$ were aged $24-$ 35 months. There were $15.3 \%(n=44)$ single-mothers and $60.3 \%(n=173)$ mothers had not completed any formal education. The most common playthings available included $64.5 \% \quad(n=185)$ children who played with homemade toys and $69.0 \%(n=198)$ of children who play with household objects. In parenting practices, $73.9 \%(n=212)$ of children experienced any violent discipline, $43.2 \%(n=124)$ had inadequate care, and $49.1 \%$ $(n=141)$ of mothers reported engaging in four or more activities to promote learning. More children with HIE were stunted ( $n=45 / 98,61.6 \%)$, underweight ( $n=43 / 98$, $44.7 \%)$, and wasted $(n=8 / 98,11.0 \%)$ than children born preterm/LBW among whom $56.4 \%(n=101 / 189)$ were stunted, 29.0\% ( $n=54 / 189)$ were underweight and 3.9\% $(n=7 / 189)$ were wasted. Overall, $74.2 \%$ of children $(n=$ 213) were at-risk for developmental delay, with $72.2 \%$ $(n=135 / 187)$ of preterm/LBW children and $89.7 \%(n=$ 85/97) of children with HIE. Potential disability was reported by the caregiver for $74.2 \%$ of children $(n=213)$, with $68.3 \%(n=129 / 189)$ among preterm/LBW and 85.7\% $(n=84 / 98)$ among children with HIE. Half of mothers $(n=148,51.6 \%)$ reported poor mental health.

In the bivariate analysis (Table 2), at $\alpha<0.20$, maternal mental health status was associated with the child's sex $(p=0.195)$, age of the child $(p=0.050)$, household size $(p=0.077)$, caregiver's eligibility status for government social services $(p=0.057)$, socio-economic status $(p=$ $0.168)$, mother's age $(p=0.030)$, marital status $(p=$
$0.003)$, mother's literacy $(p=0.002)$, mother's level of education $(p=0.040)$, child having any picture/children's book $(p=0.098)$, child discipline $(p=0.011)$, child experiencing any inadequate care $(p=0.001)$, motherreported social support $(p=<0.001)$, months of adequate household food provision in a year $(p<0.001)$, child's access to the minimum dietary diversity ( $p=$ $0.052)$, child underweight status $(p=0.017)$, child wasting status $(p=0.067)$, and child disability as reported by the caregiver $(p=0.003)$.

Factors associated with increased odds of poor maternal mental health in the final model included caregiverreported child disability (Adjusted odds Ratio [AOR]: 2.96; 95\% Confidence Interval [CI]: 1.55-5.67) and child exposure to violent discipline (AOR: 2.29; 95\%CI: $1.17-$ 4.45) (Table 3). The odds of poor maternal mental health were significantly lower among mothers living with their partners in either legal marriage (AOR: 0.12; 95\%CI: 0.04-0.36) or cohabitating (AOR: 0.13; 95\%CI: 0.05-0.37) compared to single mothers, as well as increased number of months of adequate household food provision (AOR: 0.80; 95\%CI: 0.70-0.92).

\section{Discussion}

In this study, we found a high burden of poor maternal mental health (51.6\%) among mothers with children born preterm, LBW and/or with HIE when the children were ages $24-47$ months. This poor mental health was significantly associated with having a child with a caregiver-reported disability, single marital status, food insecurity in the household, and poor child discipline practices.

While the prevalence of poor maternal mental health in the population of Rwanda is unknown, we found about double the prevalence of poor maternal mental health in mothers of children born preterm/LBW or with HIE as compared to the general population of mothers in other low- and middle-income countries where the prevalence of maternal depression is estimated at $19-25 \%$ [47]. This finding is among the highest ranges in studies of poor maternal mental health from low- and middle-income countries (4.9-59.4\%) [19].

Three-quarters of the children in our study screened positive for potential caregiver-reported disability and odds of poor mental health were more than double among mothers caring for children with a caregiverreported disability. Similar findings were noted in Malawi where $41.2 \%$ of caregivers of children with disability, including preterm/LBW and HIE children, reported having psychological distress [48]. Caring for a child with disability can increase stress in a caregiving role, increasing risk for poor mental health. Maternal depression and negative mother-infant interactions can be exacerbated when depressed mothers perceive their 
Table 1 Clinical and socio-demographic characteristics of children, mothers, and the home environment

\begin{tabular}{|c|c|c|c|c|c|c|}
\hline & \multicolumn{2}{|c|}{ Total $(N=287)$} & \multicolumn{2}{|c|}{ Preterm/LBW $(N=189)$} & \multicolumn{2}{|c|}{ HIE (N=98) } \\
\hline & $\mathrm{N}$ & $\%$ & $\mathrm{n}$ & $\%$ & $\mathrm{n}$ & $\%$ \\
\hline \multicolumn{7}{|l|}{ Child's Sex } \\
\hline Male & 146 & $50.9 \%$ & 91 & $48.2 \%$ & 55 & $56.1 \%$ \\
\hline Female & 141 & $49.1 \%$ & 98 & $51.9 \%$ & 43 & $43.9 \%$ \\
\hline \multicolumn{7}{|l|}{ Child Age } \\
\hline 24-35 Months & 181 & $63.1 \%$ & 137 & $72.5 \%$ & 44 & $44.9 \%$ \\
\hline 36-47 Months & 106 & $36.9 \%$ & 52 & $27.5 \%$ & 54 & $55.1 \%$ \\
\hline \multicolumn{7}{|c|}{ Number of People Living in the Household } \\
\hline 2-3 People & 65 & $22.7 \%$ & 37 & $19.6 \%$ & 28 & $28.6 \%$ \\
\hline 4-5 People & 110 & $38.3 \%$ & 68 & $36.0 \%$ & 42 & $42.9 \%$ \\
\hline 6 or More & 112 & $39.0 \%$ & 84 & $44.4 \%$ & 28 & $28.6 \%$ \\
\hline \multicolumn{7}{|c|}{ Eligible for Government Social Services $(n=280)$} \\
\hline Yes (Ubudehe 1) & 31 & $11.1 \%$ & 18 & $9.8 \%$ & 13 & $13.4 \%$ \\
\hline No & 249 & $88.9 \%$ & 165 & $90.2 \%$ & 84 & $86.6 \%$ \\
\hline \multicolumn{7}{|c|}{ Socioeconomic Status } \\
\hline Poorest Tertile & 104 & $36.2 \%$ & 71 & $37.6 \%$ & 33 & $33.7 \%$ \\
\hline Middle Tertile & 89 & $31.0 \%$ & 56 & $29.6 \%$ & 33 & $33.7 \%$ \\
\hline Wealthiest Tertile & 94 & $32.8 \%$ & 62 & $32.8 \%$ & 32 & $32.7 \%$ \\
\hline
\end{tabular}

Single or Multiple Birth

$$
\begin{aligned}
& \text { Single } \\
& \text { Twins or Triplets }
\end{aligned}
$$

Birthweight in Grams, mean (SD)

Mother's Age at Interview, mean (SD)

\section{Marital Status}

Single
Married
Living with Partner (not legally married)

Mother is Literate

No
Yes

\section{Mother's Highest Level of Education Completed}

None

Primary school or Higher Completed

\section{Child Having any Picture/Children's Books}

No

Yes

No

Yes

No

Yes

$\begin{array}{llllll}230 & 80.1 \% & 135 & 71.4 \% & 95 & 96.9 \% \\ 57 & 19.9 \% & 54 & 28.6 \% & 3 & 3.1 \% \\ 2133.8 & 743.7 & 1718.1 & 380.6 & 2943.2 & 596.3 \\ 31.1 & 6.7 & 31.7 & 6.8 & 29.8 & 6.3 \\ & & & & & \\ 44 & 15.3 \% & 29 & 15.3 \% & 15 & 15.3 \% \\ 142 & 50.0 \% & 95 & 50.3 \% & 47 & 48.0 \% \\ 101 & 35.2 \% & 65 & 34.4 \% & 36 & 36.7 \% \\ & & & & & \\ 78 & 27.2 \% & 53 & 28.0 \% & 25 & 25.5 \% \\ 209 & 72.8 \% & 136 & 72.0 \% & 73 & 74.5 \% \\ & & & & & \\ 173 & 60.3 \% & 109 & 57.7 \% & 64 & 65.3 \% \\ 114 & 39.7 \% & 80 & 42.3 \% & 34 & 34.7 \% \\ & & & & & \\ 259 & 90.9 \% & 169 & 89.9 \% & 90 & 92.8 \% \\ 26 & 9.1 \% & 19 & 10.1 \% & 7 & 7.2 \%\end{array}$

Child Plays with Homemade Toys (such as dolls, cars, or other toys)

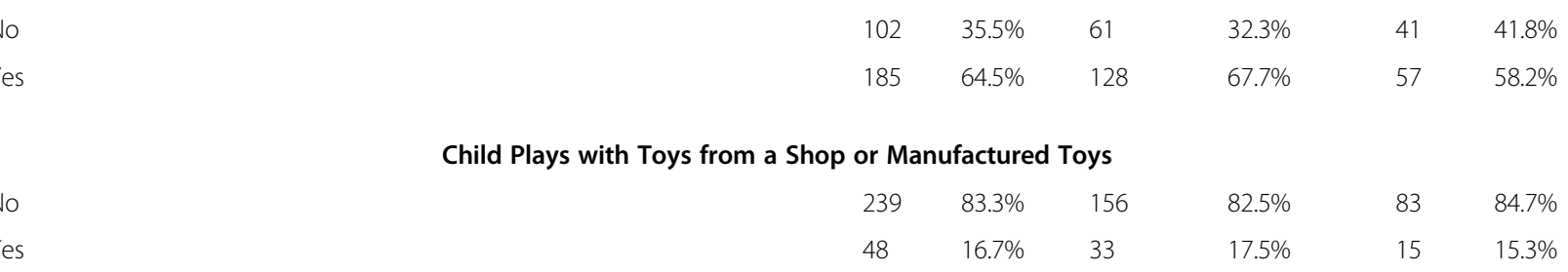


Table 1 Clinical and socio-demographic characteristics of children, mothers, and the home environment (Continued)

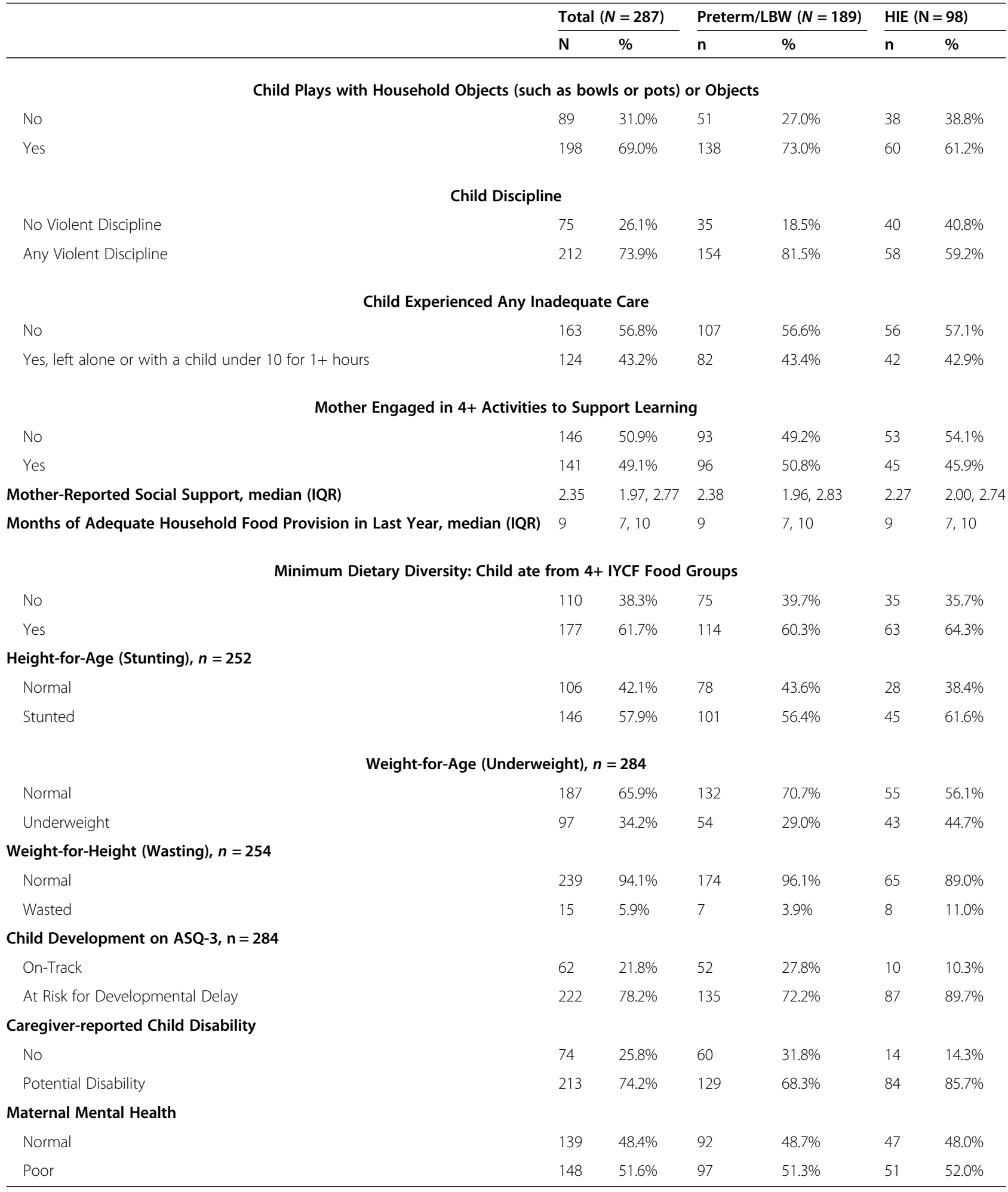

infants as temperamentally difficult [10]. This finding highlights the need to provide routine mental health screening and interventions to support mothers of children with developmental difficulties and disability.
In this study, poor mental health was also found to be strongly associated with single marital status. Single mothers' poor mental health prevalence was three times higher than married or cohabitating women. This 
Table 2 Bivariate associations between child and household factors and maternal mental health status

Variable
Child's Sex
Male
Female
Child Age
24-35 Months
36-47 Months
Child's Condition
Preterm/LBW
HIE
Number of People Living in the Household
2-3 People
4-5 People
6 or More

$\frac{\text { Normal Mental Health }}{\mathrm{n}}$

Poor Mental Health

n $\%$

Eligible for Government Social Services $(n=280)$

Yes (Ubudehe 1)

No

\section{Socioeconomic Status}

Poorest Tertile

Middle Tertile

Wealthiest Tertile

Single or Multiple Birth

single

Twins or Triplets

Birthweight in Grams, mean (SD)

Mother's Age at Interview, mean (SD)

Marital Status

Single

Married

Living with Partner (not legally married)

Mother is Literate

No

Yes

Mother's Highest Level of Education Completed

None

Primary school or Higher Completed

\section{Child Having any Picture/Children's Books}

No

Yes

Child Plays with Homemade Toys (such as dolls, cars, or other toys)

No

Yes

Child Plays with Toys from a Shop or Manufactured Toys

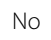

Yes

Child Plays with Household Objects (such as bowls or pots) or Objects

\section{5}

74

96

43

92

36

58

45

\section{$46.8 \%$}

$53.2 \%$

$69.1 \%$

$30.9 \%$

$66.2 \%$

$33.8 \%$

$25.9 \%$

$41.7 \%$

$32.4 \%$

$7.3 \%$

$92.7 \%$

$33.8 \%$

$28.1 \%$

$38.1 \%$

53

112

27

2080.8

30.2

11

74

54

25

113

75

64

120

17

47

92

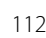

27

38

101

$80.6 \%$

$19.4 \%$

721.8

6.5

$7.9 \%$

$53.2 \%$

$38.9 \%$

18.7\%

$81.3 \%$

$54.0 \%$

$46.0 \%$

$87.6 \%$

$12.4 \%$

$33.8 \%$

$66.2 \%$

$80.6 \%$

$19.4 \%$

$27.3 \%$

$72.7 \%$
$54.7 \%$

$45.3 \%$

$57.4 \%$

$42.6 \%$

$65.5 \%$

$34.5 \%$

$19.6 \%$

$35.1 \%$

$45.3 \%$

$14.7 \%$

$85.3 \%$

$38.5 \%$

$33.8 \%$

$27.7 \%$

$79.7 \%$

$20.3 \%$

762.1

6.7

$22.3 \%$

$46.0 \%$

$31.8 \%$

$35.1 \%$

64.9\%

$66.2 \%$

$33.8 \%$

93.9\%

$6.1 \%$

$37.2 \%$

0.622

$62.8 \%$

$85.8 \%$

0.269

$14.2 \%$

$34.5 \%$

$65.5 \%$

0.195

0.050

$>0.999$

.

0.077

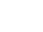

0.057

0.168

0.883

0.261

0.030

0.003

0.002

0.040

0.098

. $p$-value

Yes
51

97 
Table 2 Bivariate associations between child and household factors and maternal mental health status (Continued)

\begin{tabular}{|c|c|c|c|c|c|}
\hline \multirow[t]{2}{*}{ Variable } & \multicolumn{2}{|c|}{ Normal Mental Health } & \multicolumn{2}{|c|}{ Poor Mental Health } & \multirow[t]{2}{*}{$p$-value } \\
\hline & $\mathrm{n}$ & $\%$ & $\mathrm{n}$ & $\%$ & \\
\hline \multicolumn{6}{|l|}{ Child Discipline } \\
\hline No Violent Discipline & 46 & $33.1 \%$ & 29 & $19.6 \%$ & \multirow[t]{2}{*}{0.011} \\
\hline Any Violent Discipline & 93 & $66.9 \%$ & 119 & $80.4 \%$ & \\
\hline \multicolumn{6}{|l|}{ Child Experienced Any Inadequate Care } \\
\hline No & 93 & $66.9 \%$ & 70 & $47.3 \%$ & \multirow[t]{2}{*}{0.001} \\
\hline Yes, left alone or with a child under 10 for $1 \mathrm{~h}$ hours & 46 & $33.1 \%$ & 78 & $52.7 \%$ & \\
\hline \multicolumn{6}{|l|}{ Mother Engaged in 4+ Activities to Support Learning } \\
\hline No & 69 & $49.6 \%$ & 77 & $52.0 \%$ & \multirow[t]{2}{*}{0.724} \\
\hline Yes & 70 & $50.4 \%$ & 71 & $48.0 \%$ & \\
\hline Mother-Reported Social Support, median (IQR) & 2.6 & $2.16,2.97$ & 2.2 & $1.84,2.65$ & $<0.001$ \\
\hline Months of Adequate Household Food Provision in Last Year, median (IQR) & 9.0 & 8,10 & 8.0 & 6,10 & $<0.001$ \\
\hline \multicolumn{6}{|l|}{ Minimum Dietary Diversity: Child Ate from 4+ IYCF Food Groups } \\
\hline No & 45 & $32.4 \%$ & 65 & $43.9 \%$ & \multirow[t]{2}{*}{0.052} \\
\hline Yes & 94 & $67.6 \%$ & 83 & $56.1 \%$ & \\
\hline \multicolumn{6}{|l|}{ Height-for-Age (Stunting), $n=252$} \\
\hline Normal & 53 & $42.1 \%$ & 53 & $42.1 \%$ & \multirow[t]{2}{*}{$>0.999$} \\
\hline Stunted & 73 & $57.9 \%$ & 73 & $57.9 \%$ & \\
\hline \multicolumn{6}{|l|}{ Weight-for-Age (Underweight), $n=284$} \\
\hline Normal & 100 & $73.0 \%$ & 87 & $59.2 \%$ & \multirow[t]{2}{*}{0.017} \\
\hline Underweight & 37 & $27.0 \%$ & 60 & $40.8 \%$ & \\
\hline \multicolumn{6}{|l|}{ Weight-for-Height (Wasting), $n=254$} \\
\hline Normal & 124 & $96.9 \%$ & 115 & $91.3 \%$ & \multirow[t]{2}{*}{0.067} \\
\hline Wasted & 4 & $3.1 \%$ & 11 & $8.7 \%$ & \\
\hline \multicolumn{6}{|l|}{ Child Development on ASQ-3 } \\
\hline On-Track & 32 & $23.2 \%$ & 30 & $20.6 \%$ & \multirow[t]{2}{*}{0.668} \\
\hline At Risk for Developmental Delay & 106 & $76.8 \%$ & 116 & $79.5 \%$ & \\
\hline \multicolumn{6}{|l|}{ Caregiver-reported Child Disability } \\
\hline No & 47 & $33.8 \%$ & 27 & $18.2 \%$ & \multirow[t]{2}{*}{0.003} \\
\hline Potential Disability & 92 & $66.2 \%$ & 121 & $81.8 \%$ & \\
\hline
\end{tabular}

finding is similar to what was found by other studies that the presence of a partner in the family is associated with greater life satisfaction and better maternal mental health outcomes [49]. This finding may suggest the benefit of having a partner present in the family who is socially, economically and psychologically supportive of the caregiving role of the mother. Being married has been shown to lead to reduced stress in caregiving roles and thus resulting in better maternal mental health outcomes [50].

Mothers with poor mental health were more likely to experience more months of adequate household food provision, a measure of household food access. This link between stress of insufficient food and poor maternal mental health has been well demonstrated in highincome setting [51], with detriment to children's outcomes [52]. Household food insecurity in our sample was found along with a high prevalence of malnutrition and developmental delays. The burden of food insecurity is likely affecting children's outcomes both through the pathway of increased maternal stress and poor mental health, but also directly because lack of adequate nutrition impedes children's development [53]. Sufficient intake of micronutrients and dietary diversity is essential for optimizing children's brain development and preventing malnutrition including anemia [54].

Poor parenting practices were associated with higher odds of poor maternal mental health. In our sample, three fourths of children were exposed to violent discipline and nearly half were exposed to inadequate care with rates of both negative parenting practices significantly higher among mothers with poor mental health status. The overall high rates of harsh disciplinary practices for all children in our study were not surprising, as these practices have been shown to be common in Rwanda and other sub-Saharan African countries [55]. 
Table 3 Multivariable logistic regression predicting poor maternal mental health

\begin{tabular}{|c|c|c|c|c|c|c|}
\hline \multirow[b]{2}{*}{ Variable } & \multicolumn{3}{|c|}{ Full Model } & \multicolumn{3}{|c|}{ Final Model } \\
\hline & AOR & $95 \% \mathrm{Cl}$ & $p$-value & $A O R$ & $95 \% \mathrm{Cl}$ & $p$-value \\
\hline \multicolumn{7}{|c|}{ Child's Sex } \\
\hline Male & ref & & & & & \\
\hline Female & 1.06 & $0.55,2.04$ & 0.864 & & & \\
\hline \multicolumn{7}{|c|}{ Child Age } \\
\hline 24-35 Months & ref & & & & & \\
\hline 36-47 Months & 2.08 & $1.01,4.30$ & 0.048 & & & \\
\hline
\end{tabular}

Number of People Living in the Household

$$
\begin{aligned}
& \text { 2-3 People } \\
& \text { 4-5 People } \\
& 6 \text { or more }
\end{aligned}
$$

No

Yes (Ubudehe 1)

Single

Twins or Triplets

Single

Married

Living with Partner (not legally married)

No

Yes

None

Primary school or Higher Completed

No

Yes

\section{Child Discipline}

No Violent Discipline

Any Violent Discipline

$$
\text { No }
$$$$
\text { Yes }
$$

Mean Mother-Reported Social Support, median (IQR)

Months of Adequate Household Food Provision in Last Year, median (IQR)

\section{Marital Status}

Eligible for Government Social Services ( $n=269$ )

$$
\begin{array}{lll}
\text { ref } & & \\
0.80 & 0.31,2.03 & 0.635 \\
1.46 & 0.47,4.56 & 0.517
\end{array}
$$

ref

$$
1.87 \quad 0.49,7.18 \quad 0.363
$$

Single or Multiple Birth

$$
\begin{array}{lll}
\text { ref } & & \\
0.77 & 0.35,1.69 & 0.509
\end{array}
$$

$$
\text { ref }
$$

$0.20 \quad 0.56,0.74$

0.015

ref

$0.28 \quad 0.08,1.01 \quad 0.051$

0.12

$0.04,0.36<0.001$

Mother is Literate

$$
\begin{array}{lll}
\text { ref } & & \\
0.64 & 0.28,1.47 & 0.298
\end{array}
$$

Mother's Highest Level of Education Completed

$$
\text { ref }
$$$$
0.86 \quad 0.40,1.84 \quad 0.694
$$

Child Having any Picture/Children's books

$$
\begin{array}{lll}
\text { ref } & & \\
0.78 & 0.27,2.27 & 0.649
\end{array}
$$

$$
\text { ref }
$$$$
4.83 \quad 1.90,12.28 \quad 0.001
$$

ref

$2.29 \quad 1.17,4.45 \quad 0.015$

Child Experienced Any Inadequate Care

$\begin{array}{lll}\text { ref } & & \\ 1.49 & 0.76,2.92 & 0.246 \\ 0.59 & 0.31,1.13 & 0.110 \\ 0.89 & 0.74,1.06 & 0.186\end{array}$

0.13

$0.05,0.37<0.001$ 
Table 3 Multivariable logistic regression predicting poor maternal mental health (Continued)

\begin{tabular}{|c|c|c|c|c|c|c|}
\hline \multirow[b]{2}{*}{ Variable } & \multicolumn{3}{|c|}{ Full Model } & \multicolumn{3}{|c|}{ Final Model } \\
\hline & AOR & $95 \% \mathrm{Cl}$ & $p$-value & AOR & $95 \% \mathrm{Cl}$ & $p$-value \\
\hline \multicolumn{7}{|c|}{ Weight-for-Age (Underweight) } \\
\hline Normal & ref & & & & & \\
\hline Underweight & 1.48 & $0.63,3.47$ & 0.364 & & & \\
\hline \multicolumn{7}{|c|}{ Weight-for-Height (Wasting) } \\
\hline Normal & ref & & & & & \\
\hline Wasted & 6.92 & $0.94,51.21$ & 0.058 & & & \\
\hline \multicolumn{7}{|c|}{ Caregiver-reported Child Disability } \\
\hline No & ref & & & ref & & \\
\hline Potential Disability & 2.47 & $1.15,5.30$ & 0.02 & 2.96 & $1.55,5.67$ & 0.001 \\
\hline
\end{tabular}

This higher rate among mothers with poor mental health is supported by other studies demonstrating the increased risk of child abuse and neglect among mothers with mental health problems [56]. Further, children with caregiver-reported disability - of whom there were many in our sample - may experience violence more than non-disabled children from the time they are born [57]. Additionally, both poor maternal mental health and negative mother infant interactions can be exacerbated when a mother is perceiving her infant as having a disability [10]. These forms of compounded adversity are known to be detrimental to children's development. Holistic, integrated programs addressing maternal mental health, social needs for caregivers of children with developmental difficulties, and children's health, nutrition and developmental services are needed to optimize nurturing care among at-risk children. These services should be targeted to families with high-risk for poor outcomes, especially children born preterm/LBW and with HIE.

Our study has a few limitations. First, the sample size was small and from only one rural Rwandan district so our findings may not be generalizable to other regions. However, Kirehe district is a rural district with similar characteristics to other rural Rwandan districts. Child disability was reported by caregivers, and no diagnostic tool was used to confirm the child's disability. However, we used a standard tool and our study was limited to biological mothers who are the primary caregivers to their child and are able to identify perceived disability of their child. In addition, as we are looking only at a cross-sectional study when children were ages 24-47 months, we have a period prevalence for poor maternal health but do not know the timing of onset or duration of poor mental health which means we cannot know what is a cause of versus a result of poor maternal mental health.

\section{Conclusions}

More than half of caregivers of children born preterm, LBW and with HIE had poor mental health status, and the children had high rates of developmental delay and a caregiver-reported disability at ages $2-3$ years. Services for children with perinatal risk factors must include provision of mental health screening and treatment for mothers while simultaneously addressing early intervention and care for the child's health, nutrition, and development.

\section{Supplementary information}

Supplementary information accompanies this paper at https://doi.org/10 1186/s12884-020-03301-3.

Additional file 1.

Abbreviations

ASQ-3: Ages and Stages Questionnaire-3; HIE: Hypoxic Ischemic Encephalopathy; LBW: Low Birthweight; $\mathrm{MOH}$ : Ministry of Health; NCU: Neonatal Care Unit; PDC: Pediatric Development Clinic; WHO: World Health Organization

\section{Acknowledgements}

The manuscript was developed as part of a research-capacity building training in maternal and child health research at Partners In Health/Inshuti Mu Buzima led by Alphonse Nshimyiryo, Catherine M. Kirk, and Kathryn Beck and based on the Intermediate Operational Research Training developed by Bethany Hedt-Gauthier at Harvard Medical School.

\section{Authors' contributions}

MCA, EK, and $\mathrm{IH}$ led the study design, literature search, data cleaning and analysis, results interpretation, and writing manuscript. CMK, KB, and AN provided input in the study design, literature search, data cleaning and analysis, results interpretation, and critically reviewed the writing manuscript. $\mathrm{ACM}, \mathrm{SH}, \mathrm{SB}, \mathrm{AU}, \mathrm{KW}$, and MN contributed to the interpretation of results and review of final manuscript. CMK oversaw data collection. All authors had access to the data. The authors read and approved the final manuscript.

\section{Funding}

This study was a secondary analysis of data collected with funding from Grand Challenges Canada Saving Brains. The funder was not involved in the design of the study, the collection, analysis, interpretation of data or in writing the manuscript. 


\section{Availability of data and materials}

The datasets used and/or analyzed during the current study are available from the corresponding author on reasonable request.

\section{Ethics approval and consent to participate}

This study was approved by the Rwanda National Ethics Committee. All participating caregivers provided written informed consent for themselves and their child.

\section{Consent for publication}

Not applicable.

\section{Competing interests}

The authors declare that they have no competing interests.

\section{Author details}

${ }^{1}$ Partners In Health/Inshuti Mu Buzima, Rwinkwavu, Rwanda. ${ }^{2}$ Division of Global Health and Social Medicine, Harvard Medical School, Boston, USA. ${ }^{3}$ Rwanda Ministry of Health, Kirehe District Hospital, Kirehe, Rwanda. ${ }^{4}$ Division of General Pediatrics, Boston Children's Hospital, Boston, USA.

Received: 17 May 2020 Accepted: 29 September 2020 Published online: 21 October 2020

\section{References}

1. Chawanpaiboon S, Vogel JP, Moller A-B, Lumbiganon P, Petzold M, Hogan $D$, et al. Global, regional, and national estimates of levels of preterm birth in 2014: a systematic review and modelling analysis. Lancet Glob Health. 2019; 7(1):e37-46.

2. Lee AC, Katz J, Blencowe H, Cousens S, Kozuki N, Vogel JP, et al. National and regional estimates of term and preterm babies born small for gestational age in 138 low-income and middle-income countries in 2010. Lancet Glob Health. 2013;1(1):e26-36.

3. Lee AC, Kozuki N, Blencowe H, Vos T, Bahalim A, Darmstadt GL, et al. Intrapartum-related neonatal encephalopathy incidence and impairment at regional and global levels for 2010 with trends from 1990. Pediatr Res. 2013; 74(S1):50-72 [cited 2020 Apr 13]. Available from: http://www.nature.com/ articles/pr2013206.

4. Blencowe $\mathrm{H}$, Krasevec J, de Onis M, Black RE, An X, Stevens GA, et al. National, regional, and worldwide estimates of low birthweight in 2015, with trends from 2000: a systematic analysis. Lancet Glob Health. 2019;7(7): e849-60.

5. Lawn JE, Blencowe H, Oza S, You D, Lee ACC, Waiswa P, et al. Every newborn: progress, priorities, and potential beyond survival. Lancet. 2014; 384(9938):189-205.

6. lacovidou N, Varsami M, Syggellou A. Neonatal outcome of preterm delivery: neonatal outcome of prematurity. Ann N Y Acad Sci. 2010;1205(1): 130-4[cited 2020 Apr 13]. Available from:. https://doi.org/10.1111/j.17496632.2010.05657.x

7. Wen SW, Smith G, Yang Q, Walker M. Epidemiology of preterm birth and neonatal outcome. Semin Fetal Neonatal Med. 2004;9(6):429-35 [cited 2020 Apr 13]. Available from: https://linkinghub.elsevier.com/retrieve/pii/\$10842 75604000314

8. Zerach G, Elsayag A, Shefer S, Gabis L. Long-term maternal stress and posttraumatic stress symptoms related to developmental outcome of extremely premature infants: ELBW children mothers' stress. Stress Health. 2015;31(3): 204-13[cited 2020 Apr 13]. Available from:. https://doi.org/10.1002/smi.2547.

9. Plant KM, Sanders MR. Predictors of care-giver stress in families of preschool-aged children with developmental disabilities. J Intellect Disabil Res. 2007:51(2):109-24[cited 2020 Apr 13]. Available from:. https://doi.org/10. 1111/j.1365-2788.2006.00829.x.

10. Wachs TD, Black MM, Engle PL. Maternal depression: a global threat to Children's health, development, and behavior and to human rights. Child Dev Perspect. 2009;3(1):51-9[cited 2020 Apr 13]. Available from:. https://doi. org/10.1111/j.1750-8606.2008.00077.x.

11. Gangi S, Dente D, Bacchio E, Giampietro S, Terrin G, De Curtis M. Posttraumatic stress disorder in parents of premature birth neonates. Procedia Soc Behav Sci. 2013;82(5):882 [cited 2020 Apr 13]. Available from: https://linkinghub.elsevier.com/retrieve/pii/S1877042813014328.

12. Pisoni C, Spairani S, Manzoni F, Ariaudo G, Naboni C, Moncecchi M, et al. Depressive symptoms and maternal psychological distress during early infancy: a pilot study in preterm as compared with term mother-infant dyads. J Affect Disord. 2019;257:470-6 [cited 2020 Apr 13]. Available from: https://linkinghub.elsevier.com/retrieve/pii/S016503271930878X.

13. Schappin R, Wijnroks L, Uniken Venema MMAT, Jongmans MJ. Rethinking stress in parents of preterm infants: a meta-analysis. Bruce A, editor. PLoS One. 2013;8(2):e54992[cited 2020 Apr 13]. Available from:. https://doi.org/10. 1371/journal.pone.0054992.

14. Vigod S, Villegas L, Dennis C-L, Ross L. Prevalence and risk factors for postpartum depression among women with preterm and low-birth-weight infants: a systematic review: risk of postpartum depression in mothers of preterm and low-birth-weight infants. BJOG. 2010;117(5):540-50[cited 2020 Apr 13]. Available from:. https://doi.org/10.1111/j.1471-0528.2009.02493.x.

15. Surkan PJ, Kennedy CE, Hurley KM, Black MM. Maternal depression and early childhood growth in developing countries: systematic review and metaanalysis. Bull World Health Organ. 2011;89(8):608-615E [cited 2020 Apr 13]. Available from: http://www.who.int/entity/bulletin/volumes/89/8/11-088187. pdf.

16. Zhang S, Dang R, Yang N, Bai Y, Wang L, Abbey C, et al. Effect of Caregiver's mental health on early childhood development across different rural communities in China. Int J Environ Res Public Health. 2018;15(11):2341 [cited 2020 Apr 13]. Available from: http://www.mdpi.com/1660-46 01/15/11/2341.

17. Harpham T. Maternal mental health and child nutritional status in four developing countries. J Epidemiol Community Health. 2005;59(12):10604[cited 2020 Apr 13]. Available from:. https://doi.org/10.1136/jech.2005. 039180

18. Nkansah-Amankra S, Luchok KJ, Hussey JR, Watkins K, Liu X. Effects of maternal stress on low birth weight and preterm birth outcomes across neighborhoods of South Carolina, 2000-2003. Matern Child Health J. 2010; 14(2):215-26[cited 2020 Apr 13]. Available from:. https://doi.org/10.1007/ s10995-009-0447-4.

19. Atif $N$, Lovell $K$, Rahman A. Maternal mental health: the missing " $m$ " in the global maternal and child health agenda. Semin Perinatol. 2015;39(5):34552 [cited 2020 Apr 13]. Available from: https://linkinghub.elsevier.com/ retrieve/pii/S0146000515000543.

20. Kaaresen PI, Ronning JA, Ulvund SE, Dahl LB. A randomized, controlled trial of the effectiveness of an early-intervention program in reducing parenting stress after preterm birth. PEDIATRICS. 2006;118(1):e9-19 [cited 2020 Apr 13] Available from: http://pediatrics.aappublications.org/cgi/doi/10.1542/peds.2 005-1491.

21. Alderdice F, Newham J. Global maternal mental health: where you live matters. J Reprod Infant Psychol. 2016;34(1):1-2 [cited 2020 Apr 13]. Available from: https://www.tandfonline.com/doi/full/10.1080/02646838.2 016.1126945.

22. Hynie M, Umubyeyi B, Gasanganwa MC, Bohr Y, McGrath S, Umuziga P. Community resilience and community interventions for post-natal depression: reflecting on maternal mental health in Rwanda. In: Khanlou N, Pilkington B, editors. Women's mental health: resistance and resilience in community and society. New York: Springer; 2015.

23. Lemmon ME, Donohue PK, Parkinson C, Northington FJ, Boss RD. Parent experience of neonatal encephalopathy: the need for family-centered outcomes. J Child Neurol. 2017;32(3):286-92.

24. Anderson C, Cacola P. Implications of preterm birth for maternal mental health and infant development. MCN Am J Matern Nurs. 2017;42(2):108-14.

25. Millar KR. Prevalence and associated factors of antenatal depression in postconflict Rwanda: implications for nurse midwifery policy and practice. San Francisco: University of California, San Francisco; 2018. Available from: https://escholarship.org/uc/item/0tb688pm.

26. Umuziga MP. Assessment of common perinatal mental disorders in a selected district hospital in the eastern province of Rwanda. Cape Town: University of the Western Cape; 2014. Available from: http://etd.uwc.ac.za/ handle/11394/4283?show=full.

27. Nyirandagijimana B, Edwards JK, Venables E, Ali E, Rusangwa C, Mukasakindi $\mathrm{H}$, et al. Closing the gap: decentralising mental health care to primary care centres in one rural district of Rwanda. Public Health Action. 2017;7(3):231-6 [cited 2020 Apr 16]. Available from: http://www.ingentaconnect.com/ content/10.5588/pha.16.0130

28. Rahman A, Surkan PJ, Cayetano CE, Rwagatare P, Dickson KE. Grand challenges: integrating maternal mental health into maternal and child health Programmes. PLoS Med. 2013;10(5):e1001442 [cited 2020 Apr 16]. Available from: https://dx.plos.org/10.1371/journal.pmed.1001442. 
29. Herba CM, Glover V, Ramchandani PG, Rondon MB. Maternal depression and mental health in early childhood: an examination of underlying mechanisms in low-income and middle-income countries. Lancet Psychiatry. 2016;3(10):983-92 [cited 2020 Apr 16]. Available from: https:// linkinghub.elsevier.com/retrieve/pii/S2215036616301481.

30. Surkan PJ, Patel SA, Rahman A. Preventing infant and child morbidity and mortality due to maternal depression. Best Pract Res Clin Obstet Gynaecol. 2016;36:156-68 [cited 2020 Apr 16]. Available from: https://linkinghub. elsevier.com/retrieve/pii/S1521693416300335.

31. Ministry of Gender and Family Promotion (RW). Early childhood development policy. Kigali: Republic of Rwanda; 2016.

32. Rwanda Ministry of Health. National Community Health Strategic Plan; 2013. [cited 2018 Oct 4]. Available from: www.moh.gov.rw/fileadmin/templates/ CHD_Docs/CHD-Strategic_plan.pdf.

33. Every Preemie - SCALE. Rwanda: profile of preterm and low birth weight prevention and care; 2017. [cited 2018 Sep 20]. Available from: www. everypreemie.org/wp-content/uploads/2016/02/Rwanda.pdf.

34. Nyishime M, Borg R, Ingabire W, Hedt-Gauthier B, Nahimana E, Gupta N, et al. A retrospective study of neonatal case management and outcomes in rural Rwanda post implementation of a national neonatal care package for sick and small infants. BMC Pediatr. 2018;18(1):353.

35. National Institute of Statistics of Rwanda (NISR) [Rwanda]. Rwanda Fourth Population and Housing Census - 2012. [cited 2018 Sep 20]. Available from: http:// wnw.statistics.gov.rw/survey-period/fourth-population-and-housing-census-2012.

36. UNHCR. Operational update august 2019: Rwanda. Kigali: UNHCR; 2019. Available from: www.unhcr.org/rw.

37. Ngabireyimana E, Mutaganzwa C, Kirk CM, Miller AC, Wilson K,

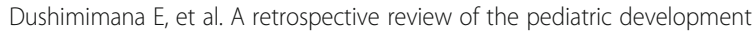
clinic implementation: a model to improve medical, nutritional and developmental outcomes of at-risk under-five children in rural Rwanda. Matern Health Neonatol Perinatol. 2017;3:13

38. Bolton P. Cross-cultural validity and reliability testing of a standard psychiatric assessment instrument without a gold standard. J Nerv Ment Dis. 2001;189(4):238-42.

39. WHO. WHO child growth standards: length/height-for-age, weight-for-age, weight-for-length, weight-for-height and body mass index-for-age: methods and development [internet]; 2006. [cited 2019 Oct 4]. Available from: https://www.who.int/childgrowth/standards/en/.

40. Kariger P, Frongillo EA, Engle P, Britto PMR, Sywulka SM, Menon P. Indicators of family Care for Development for use in multicountry surveys. J Health Popul Nutr. 2013;30(4) [cited 2020 Mar 10]. Available from: http://www. banglajol.info/index.php/JHPN/article/view/13417.

41. UNICEF. Multiple indicator cluster surveys - round 4 [internet] [internet]. New York: UNICEF; 2009. Available from: http://www.childinfo.org/mics4_ background.html.

42. Durkin M. Evaluating a ten questions screen for childhood disability: reliability and internal structure in different cultures. J Clin Epidemiol. 1995; 48(5):657-66 [cited 2020 Mar 10]. Available from: https://linkinghub.elsevier. com/retrieve/pii/089543569400163K.

43. Squires J, Twombly E, Bricker D, Potter L. ASQ-3 User's guide. Baltimore: Paul H. Brookes Publishing Company; 2009.

44. Barrera M, Ainlay SL. The structure of social support: a conceptual and empirical analysis. J Community Psychol. 1983;11(2):133-43 [cited 2020 Apr 13]. Available from: http://doi.wiley.com/10.1002/1520-6629\%28198304\%2 911\%3A2\%3C133\%3A\%3AAID-JCOP2290110207\%3E3.0.CO\%3B2-L.

45. Betancourt TS, Meyers-Ohki SE, Stulac SN, Mushashi C, Cyamatare FR, Beardslee WR. Global mental health programs for children and families facing adversity: development of the family strengthening intervention in Rwanda. In: Corbin J, editor. Children and families affected by armed conflicts in Africa: implications and strategies for helping professionals in the United States. Washington, D.C.: National Association of Social Workers Press; 2012. p. 113-42.

46. Bilinsky P, Swindale A. Months of adequate household food provisioning (MAHFP) for measurement of household food access: indicator guide (v.4) Washington, D.C.: FHI 360/FANTA; 2010.

47. Gelaye B, Rondon MB, Araya R, Williams MA. Epidemiology of maternal depression, risk factors, and child outcomes in low-income and middle-income countries. Lancet Psychiatry. 2016;3(10):973-82 [cited 2020 Apr 16]. Available from: https://linkinghub.elsevier.com/retrieve/pii/S221503661630284X.

48. Masulani-Mwale C, Kauye F, Gladstone M, Mathanga D. Prevalence of psychological distress among parents of children with intellectual disabilities in Malawi. BMC Psychiatry. 2018;18(1) [cited 2020 Apr 13]. Available from: https://bmcpsychiatry.biomedcentral.com/articles/10.1186/ s12888-018-1731-x.

49. Levis B, Rice DB, Kwakkenbos L, Steele RJ, Hagedoorn M, Hudson M, et al. Using marital status and continuous marital satisfaction ratings to predict depressive symptoms in married and unmarried women with systemic sclerosis: a Canadian scleroderma research group study: predicting depressive symptoms in married and unmarried women. Arthritis Care Res. 2016;68(8):1143-9[cited 2020 Apr 13]. Available from:. https://doi.org/10. 1002/acr.22802.

50. Atkins R. Self-efficacy and the promotion of health for depressed single mothers. Ment Health Fam Med. 2010;7(3):155-68.

51. Knowles M, Rabinowich J, Ettinger de Cuba S, Cutts DB, Chilton M. "Do You Wanna breathe or eat?": parent perspectives on child health consequences of food insecurity, trade-offs, and toxic stress. Matern Child Health J. 2016; 20(1):25-32 [cited 2020 Apr 16]. Available from: http://link.springer.com/10.1 007/s10995-015-1797-8.

52. Althoff RR, Ametti $M$, Bertmann $F$. The role of food insecurity in developmental psychopathology. Prev Med. 2016;92:106-9 [cited 2020 Apr 13]. Available from: https://linkinghub.elsevier.com/retrieve/pii/S0091 743516302183.

53. Britto PR, Lye SJ, Proulx K, Yousafzai AK, Matthews SG, Vaivada T, et al. Nurturing care: promoting early childhood development. Lancet. 2017; 389(10064):91-102 [cited 2020 Apr 16]. Available from: https://linkinghub. elsevier.com/retrieve/pii/S0140673616313903.

54. Black RE, Victora CG, Walker SP, Bhutta ZA, Christian P, de Onis M, et al. Maternal and child undernutrition and overweight in low-income and middle-income countries. Lancet Lond Engl. 2013;382(9890):427-51.

55. Cuartas J, McCoy DC, Rey-Guerra C, Britto PR, Beatriz E, Salhi C. Early childhood exposure to non-violent discipline and physical and psychological aggression in low- and middle-income countries: national, regional, and global prevalence estimates. Child Abuse Negl. 2019;92:93-105.

56. Holmes MR. Aggressive behavior of children exposed to intimate partner violence: An examination of maternal mental health, maternal warmth and child maltreatment. Child Abuse Negl. 2013;37(8):520-30 [cited 2020 Apr 13]. Available from: https://inkinghub.elsevier.com/retrieve/pii/S0145213412002669.

57. Njelesani J, Hashemi G, Cameron C, Cameron D, Richard D, Parnes P. From the day they are born: a qualitative study exploring violence against children with disabilities in West Africa. BMC Public Health. 2018;18(1):153[cited 2020 Apr 13]. Available from. https://doi.org/10.1186/s12889-018-5057-x.

\section{Publisher's Note}

Springer Nature remains neutral with regard to jurisdictional claims in published maps and institutional affiliations.

Ready to submit your research? Choose BMC and benefit from:

- fast, convenient online submission

- thorough peer review by experienced researchers in your field

- rapid publication on acceptance

- support for research data, including large and complex data types

- gold Open Access which fosters wider collaboration and increased citations

- maximum visibility for your research: over $100 \mathrm{M}$ website views per year

At $\mathrm{BMC}$, research is always in progress.

Learn more biomedcentral.com/submissions 